\title{
Therapeutic advances in non-small cell lung cancer
}

\author{
Eric Vallières, ${ }^{1}$ Solange Peters, ${ }^{2}$ Paul Van Houtte, ${ }^{3}$ Paras Dalal, ${ }^{4}$ Eric Lim ${ }^{5}$
}

'Department of Thoracic Surgery, Swedish Cancer Institute, Seattle, Washington, USA

2Department of Medical Oncology, Centre Hospitalier Universitaire Vaudois, Lausanne, Switzerland

${ }^{3}$ Department of Radiation Oncology, Institute Bordet, Université Libre de Bruxelles, Brussels, Belgium

${ }^{4}$ Department of Radiology, Harefield Hospital, London, UK

${ }^{5}$ Imperial College and Academic Division of Thoracic Surgery. Royal Brompton Hospital, London, UK

\section{Correspondence to}

Eric Lim, Academic Division of Thoracic Surgery, Royal

Brompton Hospital, Sydney

Street, London SW3 6NP, UK;

e.lim@rbht.nhs.uk

Received 2 September 2011 Accepted 6 October 2011

Published Online First

5 November 2011

\begin{abstract}
Despite decades of research, therapeutic advances in non-small cell lung cancer (NSCLC) have progressed at a painstaking slow rate with few improvements in standard surgical resection for early stage disease and chemotherapy or radiotherapy for patients with advanced disease. In the past 18 months, however, we seemed to have reached an inflexion point: therapeutic advances that are centred on improvements in the understanding of patient selection, surgery that is undertaken through smaller incisions, identification of candidate mutations accompanied by the development of targeted anticancer treatments with a focus on personalised medicine, improvements to radiotherapy technology, emergence of radiofrequency ablation (RFA), and last but by no means least, the recognition of palliative care as a therapeutic modality in its own right. The contributors to this review are a distinguished international panel of experts who highlight recent advances in each of the major disciplines.
\end{abstract}

\section{SURGERY \\ Lesser resection for peripheral lung tumours}

For years, lobectomy has been the standard of care in the management of early stage NSCLC. Limited resections have historically been considered suboptimal because of increased risk of local recurrence and are usually reserved for patients with limited cardiopulmonary reserve. Improvements in chest imaging, increased use of CT for diagnostic workup and screening for lung cancer ${ }^{1}{ }^{2}$ have led to the identification of a large number of patients harbouring small peripheral nodules suspicious for NSCLC. As very few peripheral small malignancies $(<2 \mathrm{~cm})$ were included in the studies that established lobectomy as the standard of care, ${ }^{3}$ there is now a resurgence of interest in re-evaluating the potential role of lesser resection. Although much of the data to date come from Japan, ${ }^{4}$ the Cancer and Leukemia Group B (CALGB) 140503 trial comparing lobectomy with sublobar resection for small $(<2 \mathrm{~cm})$ peripheral NSCLC is currently under way in North America to address this question. Apart from lesser resection, adjuvant brachytherapy is emerging as a potential therapeutic modality and is currently under investigation by the American College of Surgeons Oncology Group (ACOSOG) Z4032 trial, which is comparing sublobar resection with sublobar resection plus (adjuvant mesh) brachytherapy in high-risk patients with small peripheral NSCLC.

\section{Minimal access surgery}

Anatomical lung resections using video-assisted thoracoscopy (VATS) without rib spreading were first reported 20 years ago and their use in treating early-stage NSCLC seems to have gained momentum. Systematic reviews of randomised and non-randomised studies comparing VATS lobectomy with traditional open surgery concluded that VATS lobectomy is not inferior to thoracotomy lobectomy with less peri-operative morbidity. ${ }^{5}$ These cumulative data also suggested a lower rate of reported systemic recurrences and a possible improvement in survival in patients who underwent VATS lung resection. The reasons underlying the observed differences are not obvious. While some advocate lesser systemic immunity disturbances with VATS in the first few days after surgery, ${ }^{6}$ it is difficult to comprehend why $48-72 \mathrm{~h}$ of minimal perioperative alteration in systemic immunity could have such an impact on a cancer that may have been present years before diagnosis. An alternative explanation for the observed differences in survival may be due to patient selection bias within the published literature, when patients with earlier or more easily resectable disease are preferentially selected for VATS lobectomy within the non-randomised studies. A large data analysis from the Surveillance Epidemiology and End Results (SEER) registry reported higher complication rates in patients undergoing VATS lobectomy, questioning some of these perceived advantages. ${ }^{7}$ There is considerable heterogeneity in the technical conduct of both VATS and open surgery, and it is unfortunate that only two trials have ever compared the approaches head to head in a randomised fashion (combined total of 161 patients). ${ }^{89}$ Due to strong polarised opinions, a large-scale randomised trial comparing the two approaches is unlikely to ever be initiated. To add to the controversy, lobectomies undertaken with robotic assistance are now being reported as an alternative minimally invasive approach to lung cancer resection. ${ }^{10}$

\section{Surgical lymph node staging}

The extent of lymph nodes that should be removed when undertaking a lung resection for NSCLC remains a subject of debate, particularly in North America where the standard of mediastinal nodal dissection remains variable. ${ }^{11}$ Currently European guidelines recommend a systematic nodal dissection, ${ }^{12}{ }^{13}$ however a large ACOSOG trial comparing complete mediastinal lymphadenectomy with a predefined systematic nodal sampling in patients whose N1 hilar nodes were negative (by frozen section) failed to reveal any survival advantages and very minimal improvements in accuracy of staging with more aggressive nodal mediastinal dissection. ${ }^{14}$ It is important to consider that the amount of nodal staging information obtained in the 
control arm of this trial was superior to what many surgeons currently obtain and it is hoped that the results of this trial will not have a negative impact on the quality of the nodal dissection surgeons will be providing in the future, particularly in North America.

\section{CHEMOTHERAPY \\ Driver mutations in NSCLC}

Chemotherapy remains the cornerstone treatment to improve overall survival of patients with advanced NSCLC. ${ }^{15}$ Aside from modestly beneficial new regimen options ${ }^{16}{ }^{17}$ for patients with non-squamous lung cancers, the efficacy of chemotherapy seems to have reached a plateau. The concept of driver mutations emerged from the description of patients presenting with rapid, dramatic and long-lasting responses to epidermal growth factor receptor (EGFR) tyrosine kinase inhibitors (TKI). ${ }^{18}$ Since the discovery of EGFR-activating mutations, several further driver mutations have been described in patients with lung adenocarcinoma. ${ }^{19}$ These findings have led to new strategy of personalised treatment for distinct subsets of genetically defined NSCLC, depending on the availability of targeted drugs.

\section{EGFR addicted NSCLC}

The Iressa Pan-Asia Study (IPASS), ${ }^{20}$ a large randomised trial of 1217 Asian patients with adenocarcinoma with a history of light or non-smoking, reported superior survival in patients receiving a TKI as first-line treatment compared with a carboplatin-paclitaxel regimen in a retrospectively defined subgroup of patients with EGFR-mutated tumours (mainly a deletion in exon 19 in 54\% or L858R point mutation in exon 21 in 43\%).

In these patients, progression-free survival was dramatically improved in those receiving gefitinib (HR 0.48; 95\% CI 0.36 to $0.64 ; \mathrm{p}<0.001)$, as was tumour response rate $(71 \%$ vs $47 \%)$ and quality of life. Overall survival was not significantly different between the two treatment groups, probably due to the large number of patients crossing over to the treatment arm (that was allowed on the detection of progression of disease). This study demonstrated the clinical efficacy of EGFR TKIs as first-line treatment of patients who harbour EGFR-sensitive mutations, and also supported the clinical benefit of EGFR TKIs as second-line treatment.

Of interest was the lack of efficacy of gefitinib in patients who did not have a sensitising EGFR mutation as demonstrated in the IPASS study, reinforcing the rationale for chemotherapy as first choice in this subset, a finding that was confirmed with erlotinib in two prospective phase III trials presented at the American Society of Clinical Oncology (ASCO) annual meeting in 2010 and 2011 respectively. ${ }^{21} 22$ A second, similarly designed, smaller randomised $\operatorname{trial}^{23}$ reproduced the IPASS results. In a Caucasian population, the benefit of TKI treatment (either as first or second line) in patients with an EGFR-sensitising mutation was reported in a study of 217 patients (with a mutation prevalence of $17 \%$ of adenocarcinomas) with a median progression-free and overall survival of 14 and 27 months respectively. ${ }^{24}$

Since IPASS, three additional trials in Asian populations, differing by their prospective design in selected patients with EGFR mutations confirmed the superiority of first-line gefitinb $^{25}{ }^{26}$ but also erlotinib. ${ }^{27}$ In the latter study, a striking improvement of progression-free survival from 4.6 to 13.1 months (HR 0.16; 95\% CI 0.10 to 0.26; p <0.0001) was achieved compared with carboplatin-gemcitabine chemotherapy. A recent metaanalysis demonstrated first-line TKI in patients with an
EGFR-sensitising mutation increased progression-free survival and overall response rate of approximately $25 \%$ while decreasing the rates of toxicity (mainly neutropenia). ${ }^{28}$ The European Erlotinib Versus Chemotherapy (EURTAC) study, the first prospective randomised phase III trial comparing erlotinib with platinumbased chemotherapy in the context of a Caucasian population with exon 19 or 21 EGFR mutations, was presented at ASCO 2011. Similarly, in this patient population with low-rate EGFRmutation harbouring tumours, a comparable benefit was shown favouring erlotinib over a platinum-based doublet, with a progression-free survival of 9.7 vs 5.2 months (HR 0.37; $95 \% \mathrm{CI}$ 0.25 to $0.54 ; \mathrm{p}<0.0001)$, even if reported response rates were lower for erlotinib (58\%) and chemotherapy (15\%) compared with the Asian population. ${ }^{29}$

\section{EML4-ALK addicted NSCLC}

Previously described in lymphoma, neuroblastoma and myofibroblastic tumours, activating genetic alterations of anaplastic lymphoma kinase (ALK) have been identified in $2-7 \%$ of patients with NSCLC. ${ }^{30} 31$ The aberrant EML4-ALK fusion gene encodes a chimeric protein with a constitutive ALK kinase activity, and crizotinib (originally developed as a MET inhibitor) subsequently demonstrated high affinity and inhibitory capacity for tumours that harbour the activated ALK fusion gene.

A phase I/II trial in 82 patients with advanced ALK-positive disease demonstrated a response rate of $57 \%$ (disease control rate of $90 \%$ ), and an estimated probability of 6-month PFS of $72 \%$ (median not reached, 63 of 82 patients continuing crizotinib at the time of analysis). ${ }^{32}$ A good safety profile was described, with predominantly mild gastrointestinal toxicity. Crizotinib is currently being evaluated against first-line or second-line chemotherapy in phase III trials that are recruiting the (rare) patient population with ALK-rearranged advanced NSCLC.

\section{RADIOTHERAPY}

\section{Dose escalation}

Recently, a new advance in radiotherapy is the introduction of the fourth dimension-time, both during the delivery of the radiation (session) and during the entire course. Within 4- 6 weeks of treatment as the tumour responds, the field of radiation decreases reducing the amount of normal tissue that is irradiated, with an option to reduce toxicity or increase the total dose. Guckenberger et al (in a series of 13 patients) reported continuous tumour regression of $1.2 \%$ per day, and this allowed the dose to the tumour to escalate from 66 to $73 \mathrm{~Gy} .{ }^{33}$ Recently, the European Organisation for Research and Treatment of Cancer has published recommendations for planning and delivery of high-dose and high-precision radiotherapy. ${ }^{34}$ To date, several phase II trials have reported the feasibility of such an approach, and the question now is whether patients will benefit from dose escalation. This is currently being addressed by a Radiation Therapy Oncology Group phase III trial that is also seeking to evaluate the role of cetuximab as a concurrent chemoradiotherapy regimen following reports of favourable tolerability in phase II trials.

\section{Sterotactic body radiotherapy}

Stereotactic radiotherapy (SBRT) for early lung cancers is becoming an attractive alternative for patients with inoperable cancer (such as older patients or patients referred for palliative radiotherapy) because of reports of a high local control rate. In a population-based analysis of patients over 75 years, Palma et al reported an increase in the use of radiotherapy between 
1999-2001 (pre-SBRT era) and 2005-2007 from 26\% to $42 \%$ respectively and an associated improvement in survival. ${ }^{35} \mathrm{~A}$ cohort study of 462 patients who underwent surgery compared with 76 patients treated with SBRT reported better local control in patients with T1 tumours who underwent surgery but not for $\mathrm{T} 1 \mathrm{~b}$. This was because there were no differences in diseasespecific survival despite surgical patients being younger, with fewer comorbidities and having better lung function. ${ }^{36}$ In 114 matched patients there was no difference in freedom from local recurrence, disease-free survival or overall survival.

The results of SBRT need to be placed in context with the results of surgery. In a recent review of 87 patients with operable, histologically confirmed T1/2 N0 NSCLC, local recurrence, regional relapse and distant metastases occurred in 8, 13 and 19 patients respectively with 5 -year survival rates of $72 \%$ for stage Ia and $63 \%$ for stage $\mathrm{Ib}$ cancer. ${ }^{37}$ There is likely to be ongoing debate about the results of SBRT versus surgery until a randomised trial addresses this question.

\section{Concurrent and sequential radiotherapy}

Several trials have tried to answer the question of the best combined modalities: a concurrent or a sequential chemoradiotherapy. A recent meta-analysis of seven trials has reported superiority of a concurrent approach with an absolute $5.7 \%$ survival benefit at 3 years (from $18.1 \%$ to $23.8 \%$ ). ${ }^{38}$ This was largely attributed to better loco-regional control balanced against an increase in grade 3 or more acute oesophagitis (from $4 \%$ to $18 \%)$.

\section{Radiotherapy and chemotherapy}

The question of adding additional cycles of chemotherapy before or after a concurrent chemoradiotherapy approach is still not answered. Only few data are available, mainly from small phase II trials showing no major differences except less haematological toxicity and lower dose reduction for patients treated with induction chemotherapy. ${ }^{39}$

The role of a chemotherapy agent as maintenance therapy has also been questioned. Pemetrexed may be an interesting drug both during the concurrent and maintenance phase due to a low toxicity profile; however, the results of randomised trials are awaited. The different targeted agents have only been used within phase II trials and the few phase III trials did not shown any benefit. AE-941, shark cartilage extract with antiangiogenic properties, was added to chemoradiotherapy and did not improve the survival of patients with stage III disease. ${ }^{40}$ Therefore, these agents should not be used outside a clinical trial setting.

\section{Prophylactic cranial irradiation}

Prophylactic cranial irradiation was introduced in the management of small cell lung cancer and proposed for NSCLC because of the high number of brain relapses. A recent phase III trial of patients with stage III disease without evidence of progression after loco-regional treatment (surgery or radiotherapy) was closed prematurely after 356 patients out of the 1058 targeted patients because the incidence of brain metastases reduced from $18 \%$ to $7.7 \%$ after 1 year, although there was no evidence of survival benefit. ${ }^{41}$

\section{RADIOFREQUENCY ABLATION}

RFA has been used since the early 1990s to successfully treat tumours of the kidney, breast, bone, liver and adrenal glands. ${ }^{42}$ The procedure is currently performed under CT guidance by interventional radiologists or thoracic surgeons, with the majority of cases being performed under conscious sedation. ${ }^{43}$ Post-procedure follow-up has traditionally been undertaken using serial CT scans and more recently with positron emission tomography/CT to detect incomplete therapy and early recurrence. $^{44}$

There have been several case series describing the results of RFA in the management of primary and secondary lung cancers. In 2007, Simon et al reviewed 75 cases of previous untreated stage I NSCLC and reported overall survival of $78 \%, 57 \%$ and $27 \%$ at 1,2 and 5 years respectively, which compared favourably with previous studies using external beam radiotherapy in similar stage tumours. ${ }^{45-47}$ Further encouraging findings were reported by Lencioni and co-workers in 33 patients treated with RFA (13 with medically inoperable stage I NSCLC). In their study, the overall survival in patients with NSCLC was $70 \%$ and $48 \%$ at 1 and 2 years respectively, with cancer-specific survival of $92 \%$ and $73 \%$ at 1 and 2 years. ${ }^{48}$ Subgroup analysis revealed 2 -year overall survival of $75 \%$ and 2 -year cancer-specific survival of $92 \%$ in patients with inoperable stage I NSCLC. ${ }^{49}$ Most recently, Hiraki et al reported their findings in 50 patients with inoperable stage I NSCLC, with a median survival of 67 months. The overall, cancer-specific and disease-free survivals were $94 \%$, $100 \%$ and $82 \%$ at 1 year, $86 \%, 93 \%$ and $64 \%$ at 2 years, and $74 \%$, $80 \%$ and $53 \%$ at 3 years respectively, but local progression was observed in 16 (31\%) of the 52 tumours. ${ }^{50}$ The substantial difference between overall and cancer-specific survival suggests that most patients (with medically inoperable disease) die from co-morbidities rather than cancer progression.

Subgroup analysis revealed that tumour size is an important determinant of effective ablation of NSCLC and extent of ablation may be an independent risk factor for survival. Simon et al reported improved local tumour progression-free rates for tumours $<3 \mathrm{~cm}$ in diameter, ${ }^{45}$ and similar findings have been echoed by a number of other authors. Most recently, Beland et al reviewed 79 patients with NSCLC and reported $57 \%$ of cases free from recurrence at a mean follow-up of 17 months. Recurrences tended to be local to the ablated tumour site and more frequently in larger tumours ( $>4 \mathrm{~cm}$ diameter) and higher stage disease. ${ }^{51}$ Huang et al also reported significantly increased local progression in tumours of diameter $>4 \mathrm{~cm}$ in a review of 273 patients with NSCLC treated by RFA. ${ }^{52}$ Furthermore, a recent study comparing the efficacy of RFA and percutaneous cryotherapy in patients with NSCLC found that complete ablation was more frequently seen in tumours $<3 \mathrm{~cm}(76.2 \%<3 \mathrm{~cm}$ and $28.3 \%>3 \mathrm{~cm})$. The median survival was reported at 34.6 months in the complete ablation group compared with 14.4 months in the partial ablation group. ${ }^{53}$

The complications rate and safety parameters of RFA in the treatment of NSCLC have been reported to be similar to percutaneous lung biopsy. ${ }^{54}$ A systematic review reported an overall procedure-related morbidity rate of $35.7 \%$, mostly due to pneumothoraces $(28 \%)$ or pleural effusions (13.4\%). Pneumothoraces in general are self-limiting, with only $11 \%$ of RFA procedures requiring a chest drain insertion. The hospital stay ranged from 1 to 6 days. ${ }^{55}$ Of particular importance in the patients with chronic obstructive pulmonary disease, longitudinal follow-up studies have reported no significant drop in lung function after RFA for NSCLC. ${ }^{48} 56$

More recently, studies have compared outcomes for patients with stage I NSCLC undergoing percutaneous RFA with surgery. Kim et al reviewed the outcomes of eight patients with inoperable stage I NSCLC treated with RFA versus 14 patients who were surgically treated. They reported higher local recurrence in 
the RFA group but equivalent frequency of the development of distant metastatic disease with no difference in overall survival between the two groups. ${ }^{57}$ Zemlyak and co-workers reported the findings of their study of 64 patients with stage I NSCLC who were medically inoperable treated with either sublobar resection, percutaneous RFA or percutaneous cryotherapy (based on surgical preference) with similar outcomes of overall survival: $87.1 \%$ (surgery), $87.5 \%$ (RFA) and $77 \%$ (cryotherapy), with cancer-specific survival of $90.6 \%$ (surgery), $87.5 \%$ (RFA) and $90.2 \%$ (cryotherapy), but noted a (non-significant) trend towards higher recurrence in the RFA group and longer cancerfree survival in the surgical group. ${ }^{58}$ These studies suggest that despite the potential increased frequency of local recurrence in patients treated with RFA compared with those undergoing surgery, this does not have a significant detriment on overall survival.

RFA has been used in the treatment of primary lung tumours for over a decade and has been shown to be a safe and effective treatment in medically inoperable primary non-small cell lung tumours. Outcome data suggest it has survival benefit comparable to surgical resection in selected patients. With advances in radiotherapy and minimally access surgery, the time is ripe for randomised trials to ascertain the true position of this technique in the management of lung cancer.

\section{PALLIATIVE CARE}

Evidence demonstrating that palliative care interventions are significantly and objectively able to improve the quality of life of patients with specific advanced cancers remains scarce. Patients with NSCLC are prone to receive chemotherapy or radiotherapy treatments late in the course of their disease, sometimes until the end-of-life period, and often suffer from significant diseaserelated symptoms. ${ }^{59}$ In 2010, Temel and colleagues evaluated the impact of introducing palliative care early after diagnosis on patient quality of life and mood by randomising 151 ambulatory patients with NSCLC to standard oncological care with or without integrated palliative care on a minimal once monthly visit basis. ${ }^{60}$ In line with published data, ${ }^{61}{ }^{62}$ quality of life and mood were assessed at baseline and at 12 weeks with the use of the Functional Assessment of Cancer Therapy-Lung (FACT-L) scale and the Hospital Anxiety and Depression Scale, and both were significantly improved by early palliative care. Interestingly, fewer patients in the early palliative care group compared with the standard care group received aggressive treatment (33\% vs $54 \%, \mathrm{p}=0.05)$. Despite this, the median survival was longer among patients receiving early palliative care (11.6 vs 8.9 months, $\mathrm{p}=0.02$ ).

This trial demonstrates the value of initiating palliative care early in the course of treatment for advanced NSCLC. However, survival benefit must be interpreted with caution because the trial was not originally designed to evaluate this outcome, and it was not clear how much time was devoted to patients by the healthcare providers nor was there a detailed description of palliative care interventions utilised. An increase in time spent with patients with advanced NSCLC and improvement of symptoms by palliative care including depression, reduced hospitalisation and withholding ineffective chemotherapy treatments are all factors that can potentially improve patient survival and lower healthcare costs and should be studied in their own right. ${ }^{63}$

\section{Competing interests None.}

Contributors All five authors contributed to the article equally.

Provenance and peer review Commissioned; internally peer reviewed.

\section{REFERENCES}

1. Henschke CI, Yankelevitz DF, Libby DM, et al. Survival of patients with stage I lung cancer detected on CT screening. N Engl J Med 2006;355:1763-71.

2. The National Lung Screening Trial Research Team. Reduced lung-cancer mortality with low-dose computed tomographic screening. N Engl J Med 2011;365:395-409.

3. Ginsberg RJ, Rubinstein LV. Randomized trial of lobectomy versus limited resection for T1 N0 non-small cell lung cancer. Lung Cancer Study Group. Ann Thorac Surg 1995;60:615-22; discussion 622-3.

4. Fukui T, Sakakura N, Mori S, et al. Controversy about small peripheral lung adenocarcinomas: how should we manage them? J Thorac Oncol 2007;2:546-52.

5. Yan TD, Black D, Bannon PG, et al. Systematic review and meta-analysis of randomized and nonrandomized trials on safety and efficacy of video-assisted thoracic surgery lobectomy for early-stage non-small-cell lung cancer. J Clin Oncol 2009;27:2553-62.

6. Yim AP, Wan S, Lee TW, et al. VATS lobectomy reduces cytokine responses compared with conventional surgery. Ann Thorac Surg 2000;70:243-7.

7. Gopaldas RR, Bakaeen FG, Dao TK, et al. Video-assisted thoracoscopic versus open thoracotomy lobectomy in a cohort of 13,619 patients. Ann Thorac Surg 2010;89:1563-70.

8. Kirby TJ, Mack MJ, Landreneau RJ, et al. Lobectomy-video-assisted thoracic surgery versus muscle-sparing thoracotomy. A randomized trial. J Thorac Cardiovasc Surg 1995;109:997-1001; discussion 1001-2.

9. Sugi K, Kaneda Y, Esato K. Video-assisted thoracoscopic lobectomy achieves a satisfactory long-term prognosis in patients with clinical stage IA lung cancer. World J Surg 2000;24:27-30; discussion 30-1.

10. Gharagozloo F, Margolis M, Tempesta B, et al. Robot-assisted lobectomy for earlystage lung cancer: report of 100 consecutive cases. Ann Thorac Surg 2009;88:380-4.

11. Little AG, Rusch VW, Bonner JA, et al. Patterns of surgical care of lung cancer patients. Ann Thorac Surg 2005;80:2051-6; discussion 2056.

12. Lardinois D, De Leyn $P$, Van Schil $P$, et al. ESTS guidelines for intraoperative lymph node staging in non-small cell lung cancer. Eur J Cardiothorac Surg 2006:30:787-92

13. Lim $\mathbf{E}$, Baldwin D, Beckles $\mathrm{M}$, et al. Guidelines on the radical management of patients with lung cancer. Thorax 2010;65 Suppl 3:iii1-27.

14. Darling GE, Allen MS, Decker PA, et al. Randomized trial of mediastinal lymph node sampling versus complete lymphadenectomy during pulmonary resection in the patient with NO or N1 (less than hilar) non-small cell carcinoma: results of the American College of Surgery Oncology Group Z0030 Trial. J Thorac Cardiovasc Surg 2011:141:662-70.

15. Anon. Chemotherapy in non-small cell lung cancer: a meta-analysis using updated data on individual patients from 52 randomised clinical trials. Non-small Cell Lung Cancer Collaborative Group. BMJ 1995;311:899-909.

16. Sandler A, Gray R, Perry MC, et al. Paclitaxel-carboplatin alone or with bevacizumab for non-small-cell lung cancer. N Engl J Med 2006;355:2542-50.

17. Scagliotti GV, Parikh P, von Pawel J, et al. Phase III study comparing cisplatin plus gemcitabine with cisplatin plus pemetrexed in chemotherapy-naive patients with advanced-stage non-small-cell lung cancer. J Clin Oncol 2008:26:3543-51.

18. Sharma SV, Bell DW, Settleman J, et al. Epidermal growth factor receptor mutations in lung cancer. Nat Rev Cancer 2007;7:169-81.

19. Pao W, Girard N. New driver mutations in non-small-cell lung cancer. Lancet Oncol 2011:12:175-80

20. Mok TS, Wu YL, Thongprasert S, et al. Gefitinib or carboplatin-paclitaxel in pulmonary adenocarcinoma. N Engl J Med 2009:361:947-57.

21. Gridelli CF, Feld R. International multicenter randomized phase III study of first-line erlotinib (E) followed by second-line cisplatin plus gemcitabine (CG) versus first-line CG followed by second-line $E$ in advanced non-small cell lung cancer (aNSCLC): the TORCH trial. J Clin Oncol 2010;28(Suppl):abstr 7508.

22. Thomas M, Reuss A, Fischer JR, et al. Randomized phase II trial of erlotinib (E)/ bevacizumab (B) compared with cisplatin (P)/gemcitabine (G) plus B in first-line treatment of advanced nonsquamous (NS) non-small cell lung cancer (NSCLC). J Clin Oncol 2011;29(Suppl):abstr 7504.

23. Lee JS, Kim S. A randomized phase III study of gefitinib versus standard chemotherapy (gemcitabine plus cisplatine) as first-line treatment for never-smokers with advanced or metastatic adenocarcinoma of the lung. J Thorac Oncol 2009;4: S283.

24. Rosell R, Moran T, Queralt C, et al. Screening for epidermal growth factor receptor mutations in lung cancer. N Engl J Med 2009;361:958-67.

25. Maemondo M, Inoue A, Kobayashi K, et al. Gefitinib or chemotherapy for non-smallcell lung cancer with mutated EGFR. N Engl J Med 2010:362:2380-8.

26. Mitsudomi T, Morita S, Yatabe Y, et al. Gefitinib versus cisplatin plus docetaxel in patients with non-small-cell lung cancer harbouring mutations of the epidermal growth factor receptor (WJTOG3405): an open label, randomised phase 3 trial. Lancet Oncol 2010;11:121-8.

27. Zhou C, Wu YL, Chen G, et al. Erlotinib versus chemotherapy as first-line treatment for patients with advanced EGFR mutation-positive non-small-cell lung cancer (OPTIMAL, CTONG-0802): a multicentre, open-label, randomised, phase 3 study. Lancet Oncol 2011;12:735-42.

28. Bria E, Milella M, Cuppone F, et al. Outcome of advanced NSCLC patients harboring sensitizing EGFR mutations randomized to EGFR tyrosine kinase inhibitors or chemotherapy as first-line treatment: a meta-analysis. Ann Oncol 2011;22:2277-85. 
29. Rosell R, Gervais R, Vergnenegre A, et al. Erlotinib versus chemotherapy (CT) in advanced non-small cell lung cancer (NSCLC) patients (p) with epidermal growth factor receptor (EGFR) mutations: interim results of the European Erlotinib Versus Chemotherapy (EURTAC) phase III randomized trial. J Clin Oncol 2011;29(Suppl): abstr 7503.

30. Choi YL, Takeuchi K, Soda M, et al. Identification of novel isoforms of the EML4-ALK transforming gene in non-small cell lung cancer. Cancer Res 2008;68:4971-6.

31. Soda M, Choi YL, Enomoto $M$, et al. Identification of the transforming EML4-ALK fusion gene in non-small-cell lung cancer. Nature 2007:448:561-6.

32. Kwak EL, Bang YJ, Camidge DR, et al. Anaplastic lymphoma kinase inhibition in nonsmall-cell lung cancer. N Engl J Med 2010;363:1693-703.

33. Guckenberger $\mathbf{M}$, Wilbert J, Richter $\mathrm{A}$, et al. Potential of adaptive radiotherapy to escalate the radiation dose in combined radiochemotherapy for locally advanced nonsmall cell lung cancer. Int J Radiat Oncol Biol Phys 2011;79:901-8.

34. De Ruysscher D, Faivre-Finn C, Nestle U, et al. European Organisation for Research and Treatment of Cancer recommendations for planning and delivery of high-dose, high-precision radiotherapy for lung cancer. J Clin Oncol 2010:28:5301-10.

35. Palma D, Visser 0, Lagerwaard FJ, et al. Impact of introducing stereotactic lung radiotherapy for elderly patients with stage I non-small-cell lung cancer: a populationbased time-trend analysis. J Clin Oncol 2010;28:5153-9.

36. Crabtree TD, Denlinger CE, Meyers BF, et al. Stereotactic body radiation therapy versus surgical resection for stage I non-small cell lung cancer. J Thorac Cardiovasc Surg 2010;140:377-86.

37. Onishi H, Shirato H, Nagata Y, et al. Stereotactic Body Radiotherapy (SBRT) for operable stage I non-small-cell lung cancer: can SBRT be comparable to surgery? Int J Radiat Oncol Biol Phys. Published Online First: 15 July 2010. doi:10.1016/j. ijrobp.2009.07.1751.

38. Auperin A, Le Pechoux C, Rolland E, et al. Meta-analysis of concomitant versus sequential radiochemotherapy in locally advanced non-small-cell lung cancer. J Clin Oncol 2010;28:2181-90

39. Senan S, Cardenal F, Vansteenkiste J, et al. A randomized phase II study comparing induction or consolidation chemotherapy with cisplatin-docetaxel, plus radical concurrent chemoradiotherapy with cisplatin-docetaxel, in patients with unresectable locally advanced non-small-cell lung cancer. Ann Oncol 2011:22:553-8.

40. Lu C, Lee JJ, Komaki R, et al. Chemoradiotherapy with or without AE-941 in stage III non-small cell lung cancer: a randomized phase III trial. J Natl Cancer Inst 2010;102:859-65

41. Gore EM, Bae K, Wong SJ, et al. Phase III comparison of prophylactic cranial irradiation versus observation in patients with locally advanced non-small-cell lung cancer: primary analysis of radiation therapy oncology group study RTOG 0214. J Clin Oncol 2011;29:272-8.

42. Gandhi NS, Dupuy DE. Image-guided radiofrequency ablation as a new treatment option for patients with lung cancer. Semin Roentgenol 2005;40:171-81.

43. Hoffmann RT, Jakobs TF, Lubienski A, et al. Percutaneous radiofrequency ablation of pulmonary tumors - is there a difference between treatment under general anaesthesia and under conscious sedation? Eur J Radiol 2006;59:168-74.

44. Okuma T, Matsuoka T, Yamamoto A, et al. Assessment of early treatment response after CT-guided radiofrequency ablation of unresectable lung tumours by diffusionweighted MRI: a pilot study. Br J Radiol 2009;82:989-94.
45. Simon CJ, Dupuy DE, DiPetrillo TA, et al. Pulmonary radiofrequency ablation: longterm safety and efficacy in 153 patients. Radiology 2007;243:268-75.

46. Talton BM, Constable WC, Kersh CR. Curative radiotherapy in non-small cell carcinoma of the lung. Int J Radiat Oncol Biol Phys 1990:19:15-21.

47. Qiao X, Tullgren 0 , Lax I, et al. The role of radiotherapy in treatment of stage I nonsmall cell lung cancer. Lung Cancer 2003:41:1-11.

48. Lencioni R, Crocetti $L$, Cioni $R$, et al. Response to radiofrequency ablation of pulmonary tumours: a prospective, intention-to-treat, multicentre clinical trial (the RAPTURE study). Lancet Oncol 2008;9:621-8.

49. Hiraki T, Gobara $\mathrm{H}$, lishi $\mathrm{T}$, et al. Percutaneous radiofrequency ablation for clinical stage I non-small cell lung cancer: results in 20 nonsurgical candidates. J Thorac Cardiovasc Surg 2007;134:1306-12.

50. Hiraki T, Gobara H, Mimura $\mathrm{H}$, et al. Percutaneous radiofrequency ablation of clinical stage I non-small cell lung cancer. J Thorac Cardiovasc Surg 2011;142:24-30.

51. Beland MD, Wasser EJ, Mayo-Smith WW, et al. Primary non-small cell lung cancer: review of frequency, location, and time of recurrence after radiofrequency ablation. Radiology 2010;254:301-7.

52. Huang L, Han Y, Zhao J, et al. Is radiofrequency thermal ablation a safe and effective procedure in the treatment of pulmonary malignancies? Eur J Cardiothorac Surg 2011;39:348-51

53. Choe YH, Kim SR, Lee KS, et al. The use of PTC and RFA as treatment alternatives with low procedural morbidity in non-small cell lung cancer. Eur J Cancer 2009;45:1773-9

54. Simon CJ, Dupuy DE. Current role of image-guided ablative therapies in lung cancer Expert Rev Anticancer Ther 2005;5:657-66.

55. Zhu JC, Yan TD, Morris DL. A systematic review of radiofrequency ablation for lung tumors. Ann Surg Oncol 2008:15:1765-74.

56. Lanuti M, Sharma A, Digumarthy SR, et al. Radiofrequency ablation for treatment of medically inoperable stage I non-small cell lung cancer. J Thorac Cardiovasc Surg 2009;137:160-6.

57. Kim SR, Han HJ, Park SJ, et al. Comparison between surgery and radiofrequency ablation for stage I non-small cell lung cancer. Eur J Radiol. Published Online First: 8 February 2011. doi:10.1016/j.ejrad.2010.12.091.

58. Zemlyak A, Moore WH, Bilfinger TV. Comparison of survival after sublobar resections and ablative therapies for stage I non-small cell lung cancer. J Am Coll Surg 2010;211:68-72.

59. Hopwood P, Stephens RJ. Symptoms at presentation for treatment in patients with lung cancer: implications for the evaluation of palliative treatment. The Medical Research Council (MRC) Lung Cancer Working Party. Br J Cancer 1995;11:633-6.

60. Temel JS, Greer JA, Muzikansky A, et al. Early palliative care for patients with metastatic non-small-cell lung cancer. N Engl J Med 2010;363:733-42.

61. Bakitas $\mathbf{M}$, Lyons KD, Hegel MT, et al. Effects of a palliative care intervention on clinical outcomes in patients with advanced cancer: the Project ENABLE ॥ randomized controlled trial. JAMA 2009;302:741-9.

62. Follwell M, Burman D, Le LW, et al. Phase II study of an outpatient palliative care intervention in patients with metastatic cancer. J Clin Oncol 2009;27:206-13.

63. Zimmermann C, Riechelmann R, Krzyzanowska M, et al. Effectiveness of specialized palliative care: a systematic review. JAMA 2008;299:1698-709. 